\title{
ZnO Epitaxy on (111) Silicon using Intervening Bixbyite Oxide Buffer Layers
}

\author{
M.B. Katz, ${ }^{*}$ W. Guo, ${ }^{*}$ A. Allenic, ${ }^{*}$ Y.B. Chen, ${ }^{*}$ Y. Zhang, ${ }^{*}$ C.T. Nelson, ${ }^{*}$ T. Heeg, ${ }^{* *}$ W. Tian, ${ }^{* *}$ \\ C. Adamo, ${ }^{* *}$ D.G. Schlom, ${ }^{* *}$ and X.Q. Pan* \\ * Department of Materials Science and Engineering, University of Michigan, Ann Arbor, MI 48109 \\ ** Department of Materials Science and Engineering, Cornell University, Ithaca, NY 14853
}

$\mathrm{ZnO}$ has attracted intense interest of research in recent years due to possible replacement for $\mathrm{GaN}$ for photodiode [1] and lasing applications [2]. $\mathrm{ZnO}$ has a comparable band gap to $\mathrm{GaN}, 3.37 \mathrm{eV}$, while having a two-fold increase in exciton binding energy, $60 \mathrm{meV}$ vs. $20 \mathrm{meV}$, allowing for brighter emission at lower thresholds. The commercial availability of bulk $\mathrm{ZnO}$ single crystals could also substantially reduce the cost of $\mathrm{ZnO}$-based devices relative to that of GaN-based devices. One significant hurdle in developing $\mathrm{ZnO}$ based multifunctional devices, however, has been integration with silicon $(\mathrm{Si})$. Direct growth of $\mathrm{ZnO}$ on Si has proven extremely difficult, resulting almost exclusively in polycrystalline and textured films, due to the formation of oxide layers on the Si surface, reactivity between $\mathrm{ZnO}$ and $\mathrm{Si}$, a large lattice mismatch $(15.4 \%)$, and a large mismatch in thermal expansion (60\%). These effects, though, can be mitigated through the employment of a buffer layer.

Bixbyite oxides are one such candidate for buffering $\mathrm{ZnO}$ growth on $\mathrm{Si}$. They have the cubic structure (space group Ia $\overline{3})$ in the stoichiometry $\mathrm{M}_{2} \mathrm{O}_{3}(\mathrm{M}=\mathrm{Sc}, \mathrm{Lu}, \mathrm{Y}, \mathrm{Gd}$ ) which are nonreacting and thermodynamically stable with both $\mathrm{Si}$ and $\mathrm{ZnO}$. In this work the epitaxial thin films of $\mathrm{Sc}_{2} \mathrm{O}_{3}$, $\mathrm{Lu}_{2} \mathrm{O}_{3}$, and $\mathrm{Gd}_{2} \mathrm{O}_{3}$ with thicknesses varying from 1 to $100 \mathrm{~nm}$ were grown on (111) p-Si by reactive molecular beam epitaxy. $\mathrm{ZnO}$ thin films with thicknesses ranging from $300 \mathrm{~nm}$ to $2 \mu \mathrm{m}$ were then grown with two steps by pulsed laser deposition. A low-temperature nucleation layer $(\sim 10 \mathrm{~nm})$ was grown at $240{ }^{\circ} \mathrm{C}$, followed the growth of a high temperature thick film at $600{ }^{\circ} \mathrm{C}$. Microstructure and defects of $\mathrm{ZnO}$ films were then studied using high-resolution transmission electron microscopy (TEM), photoluminescence (PL) spectroscopy, and x-ray diffraction (XRD). The orientation relationship is found to be $(0001)[1 \overline{2} 10]_{\mathrm{ZnO}}\left\|(111)\left[\begin{array}{ll}1 & 10\end{array}\right]_{\mathrm{M}_{2} \mathrm{O}_{3}}\right\|(111)\left[\begin{array}{ll}1 & 0\end{array}\right]_{\mathrm{Si}}$.

Figs. 1(a-c) show the microstructure of the $\mathrm{ZnO}$ films grown on Si substrates with the $\mathrm{Sc}_{2} \mathrm{O}_{3}, \mathrm{Lu}_{2} \mathrm{O}_{3}$, and $\mathrm{Gd}_{2} \mathrm{O}_{3}$ buffer layers, respectively. All films consist of smooth surface and sharp interfaces. A thin amorphous layer of $\mathrm{SiO}_{x}$ was observed between $\mathrm{Si}$ and the $\mathrm{M}_{2} \mathrm{O}_{3}$ buffer layers despite the epitaxial nature of the buffers and $\mathrm{ZnO}$ films (Fig. 2). These amorphous layers are not present, though, before $\mathrm{ZnO}$ deposition (Fig. 3), and can thus be concluded to have formed during subsequent $\mathrm{ZnO}$ growth by oxygen diffusion through the buffer layers. PL and XRD reveal excellent optical and structural properties compared with $\mathrm{ZnO}$ films grown on other substrates such as saphhire $[3,4]$.

[1] D.M. Bagnall et al., Appl. Phys. Lett. 70 (1997) 2230

[2] A. Tsukazaki et al., Nat. Mater. 4 (2004) 42

[3] W. Guo et al., Appl. Phys. Lett. 92 (2008) 071201

[4] W. Guo et al., Appl. Phys. Lett. 94 (2009) 122107 


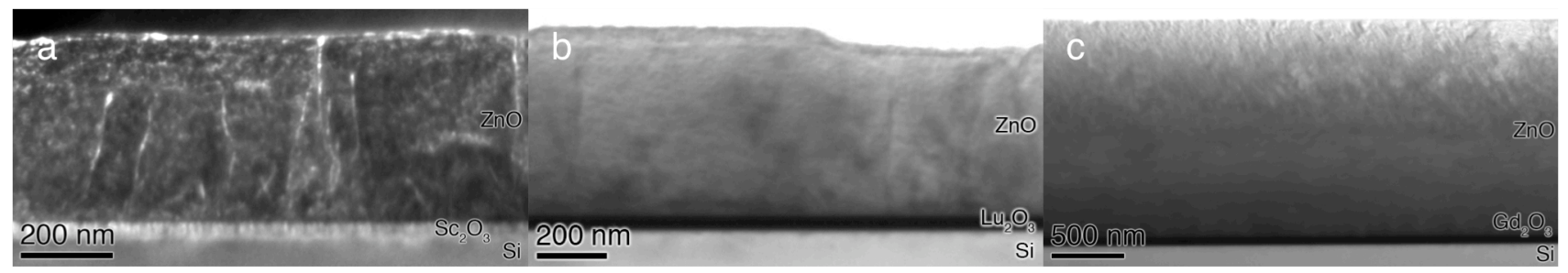

FIG. 1. TEM survey micrographs of $\mathrm{ZnO}$ films on (a) $\mathrm{Sc}_{2} \mathrm{O}_{3}$, (b) $\mathrm{Lu}_{2} \mathrm{O}_{3}$, and (c) $\mathrm{Gd}_{2} \mathrm{O}_{3}$ buffer layers.

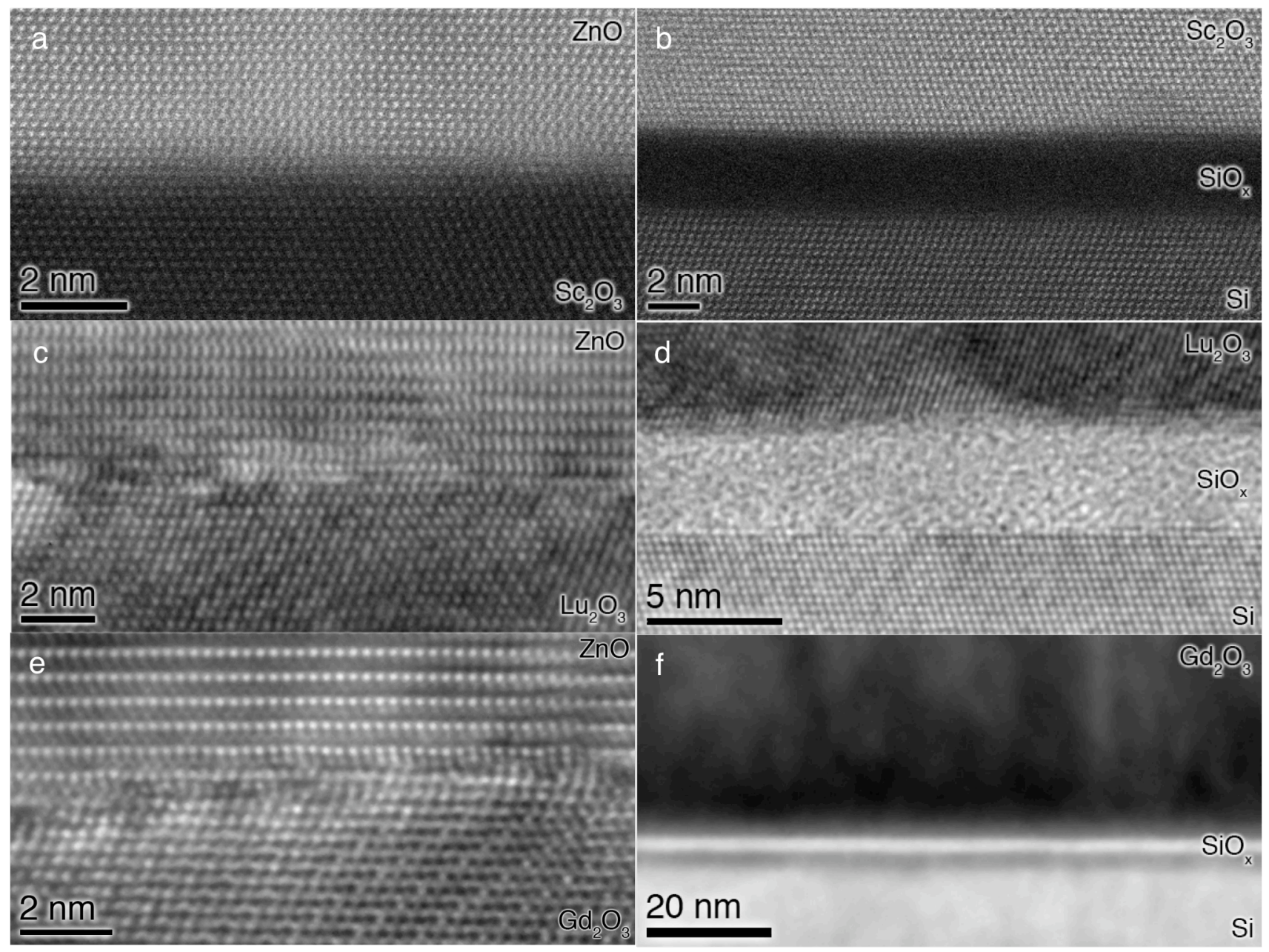

FIG. 2. HR-STEM and HR-TEM micrographs of the $\mathrm{ZnO} / \mathrm{M}_{2} \mathrm{O}_{3}$ and $\mathrm{M}_{2} \mathrm{O}_{3} / \mathrm{Si}$ interface regions for $(\mathrm{a}, \mathrm{b}) \mathrm{Sc}_{2} \mathrm{O}_{3},(\mathrm{c}, \mathrm{d}) \mathrm{Lu}_{2} \mathrm{O}_{3}$, and $(\mathrm{e}, \mathrm{f}) \mathrm{Gd}_{2} \mathrm{O}_{3}$ buffer layers, respectively.

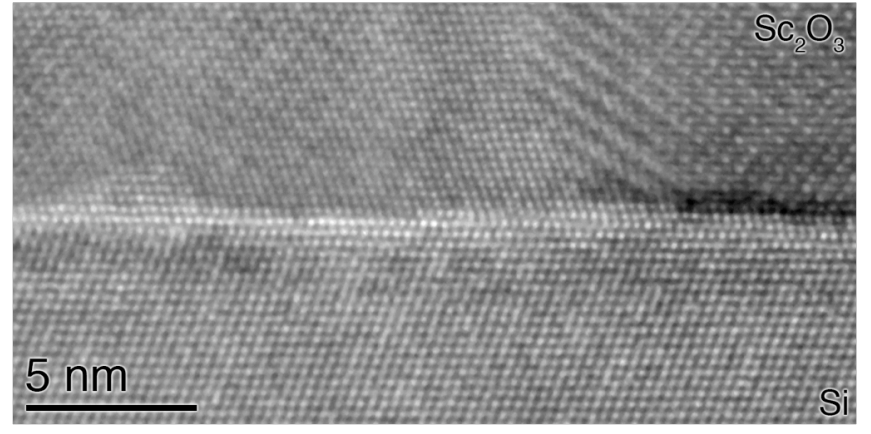

FIG. 3. HR-TEM image of the $\mathrm{Sc}_{2} \mathrm{O}_{3} / \mathrm{Si}$ interface before subsequent $\mathrm{ZnO}$ growth, showing no amorphous $\mathrm{SiO}_{x}$ layer. 